\title{
Research on Blended Learning Based on Competition
}

\author{
Bocheng Liu ${ }^{1, a,}$, Jianfeng $\mathrm{Xu}^{1, \mathrm{~b}}$, Mengmeng Shi ${ }^{1, \mathrm{c}}$ \\ ${ }^{1}$ School of Software,Nanchang University,Nanchang, 330031, China \\ ajsjjcjx@163.com,bJianfeng_x@ncu.edu.cn,c767455480@qq.com
}

Keywords: blended learning, SPOC, data mining

\begin{abstract}
Currently,data mining in the background of big data has become the core technology of big data analysis.Data mining engineers and big data analysts have gradually become more and more popular.This article explores the blended learning based on the combination of SPOC and competition driven, and conducts teaching practice in data mining courses to verify teaching effectiveness.Focusing on the teaching methods reform that combines theory and practice,so that competitions can be a useful supplement to daily teaching.Combined with competition activities to improve curriculum assessment system.After practice,preliminary verified its feasibility and effects.
\end{abstract}

\section{Introduction}

Data Mining is one of the core courses in software engineering.Currently,data mining in the background of big data has become the core technology of big data analysis.Data mining engineers and big data analysts have gradually become more and more popular.Data mining itself is a complex subject with distinct intersection. It has not only strong theories, but also strong practical significance,which focuses on cultivating students' ability to innovate and solve comprehensive problems.However, the traditional teaching method mainly focuses on the theory teaching ,the cultivation of ability to innovate and solve comprehensive problems has always been the shortcomings of it.

With the development of educational information technology and the update of educational philosophy, schools and teachers pay more attention to the improvement of students' individualized development and comprehensive quality[1].Since 2012, the craze of MOOC has caused serious concern from the domestic higher education sector.In March 2015, < The Key Points of Educational Information Work in 2015> issued by the General Office of the Ministry of Education pointed out: "Insisting on the core concept of promoting the integration of information technology and education and teaching."Blended learning conforms to the concept of this teaching reform, bringing new ideas to the course teaching.

Many institutions and experts both at home and abroad have studied blended learning. In traditional American schools, teachers often take a blended approach to teaching[2]. The president of Penn State University spoke highly of blended learning, regarding it as "an inevitable trend of development in today's higher education field." In China, since the early 21st century, blended learning has become a hot topic in the field of education. At present, blended learning is developing rapidly.It has been widely used in many fields such as education and training institutions, and its achievements have also been quite remarkable[3]. With the continuous expansion of blended learning superiority, all colleges have strengthen their efforts to hybrid learning. They advocate effective blended learning activities and utilize advanced teaching techniques to achieve hybrid learning from the perspective of education and teaching.

This article explores the blended learning based on the combination of SPOC and competition driven, and conducts teaching practice in data mining courses to verify teaching effectiveness.

\section{Blended learning application}

SPOC(Small Private Online Courses) is a type of online open course that is more refined and 
smaller than MOOC. It combines the advantages of large-scale online open courses and can make up for the deficiency of traditional classroom teaching. Therefore, SPOC has created the conditions for integrating MOOC into university classrooms and improving the quality of classroom teaching.

Join MOOC courses ,use SPOC so that the students can enroll in class registration, follow the SPOC courses to complete the relevant homework. Teachers can delete the original MOOC contents and add contents. Through the network platform, we pay close attention to each student's log in times, viewing times, homework completion, and obtain the students' learning status and evaluation scores on the Internet as part of their usual grades to supervise their after-hours study. The introduction of the teaching mode will further stimulate students' learning participation and enthusiasm take full advantage of their spare time, and give priority to answering questions and doubts in class lectures. They will truly take passive acceptance into active learning and enhance their learning initiative.

\subsection{Promote the change of teaching mode from "teaching-oriented" to "learning-oriented" to improve the enthusiasm of students' learning and learning effect}

Those knowledge points that did not be understood in class can be remedied by watching SPOC teaching videos after class. Before class, watch the SPOC videos to preview with questions to listen to your class teachers in class, or with the problem to play back the SPOC videos after class so that learning is more efficient and targeted; The regular and diversified on-line training and automated test work on SPOC not only provides students with more training opportunities, but also trains students' consciousness of learning; The assignments allow multiple submissions to get the highest score.Once the students submit their assignments and find some errors, and then submit again, they finally get a satisfactory score.Only in this way can the students strengthen what they have learned in the practice and achieve more practice to reach the goal of "do in learning and learning in doing."

\subsection{Enhance teachers' teaching ability}

First of all, SPOC teachers can easily acquire a large amount of teaching resources in the MOOC courses and reuse them. In this way, the teaching mode can be transformed from the original practice of "speaking more and training less" to "speaking less and training more", from the original all-inclusive transition to only focus on heavy and difficult issues. Secondly, SPOC teachers have access to an online Q \& A team, and even if the SPOC teachers do not have time, there will be MOOC teachers or other SPOC teachers and teaching assistants to answer questions and help everyone. In addition, SPOC facilitates teachers to manage students in their own class and view their SPOC academic records, and saves time in class assignments and after-school assignments due to regular SPOC assignments ,periodic deadlines, automatic grading, and automatic statistics.

\section{Based on competition-driven blended learning practice}

In recent years, as big data mining becomes a hot spot of application all over the world, many enterprises or research institutes begin to solicit solutions to some of the world's data mining issues in an international competition. In addition to some of the major international conferences each year, there will be such a competition topic, a number of professional data mining international competition websites are also increasingly attracted the attention of the industry. Kaggle is the world's most popular with crowsouring strategy for providing competing platforms for data analysis and forecasting models for technology companies, research institutes and even college curricula. The topics of these competitions generally reflect the most popular research topics in the world at that time and can reflect the new trends in the development of data mining technologies. The international competition will be introduced into the data mining classes. The teaching of data mining theory will be combined with popular competitions of that year, and teaching and evaluation tools will be reformed so as to guide students to participate in the competitions and to promote their studies and effectively enhance students' ability to innovate and solve comprehensive problems. 


\subsection{Construction of a knowledge system based on race-driven data mining courses}

The setting of curriculum not only concerned about the content of the curriculum, but also to consided the basic education professional ability, the sustainable development and other essential questions of students. Data mining is an interdisciplinary discipline that combines knowledge of multiple disciplines such as database technology, statistics, machine learning, neural networks, knowledge systems, information retrieval, high performance computing and visualization. Moreover, this course includes not only all kinds of theoretical knowledge, but also related practical skills. The whole teaching process is an important way to cultivate and improve students' ability to innovate and to solve problems synthetically. Therefore, the primary task of teaching is to construct the core knowledge structure of the whole course.

The knowledge system before the reform mainly introduces the traditional data mining technology and development, and learns to master the use of Microsoft SQL Server for association rules data mining, decision tree mining, clustering mining and so on, which can not keep up with technological development and lack actual combat ability. After the reform, the international competition and curriculum system design will be closely integrated so that daily teaching can infiltrate and reflect the current major international research trends. At the same time, some knowledge related to competitions should be included in the teaching plan, so that the combination of curriculum and practical application can promote the teaching content and knowledge system reform through competition, and provide support for the reform through teaching reform.

Research the main topics of international well-known data mining competitions in recent 3 years, and determine the main research trends. According to the survey results to determine the latest knowledge structure, the reform curriculum system are shown in Table 1.

Table 1 Knowledge System of Data Mining Course

\begin{tabular}{|l|l|l|l|}
\hline \multicolumn{5}{|c|}{ Algorithm } & \multicolumn{1}{c|}{ Case(dataset) } & \multicolumn{1}{c|}{ SPOC case } \\
\hline \multirow{5}{*}{ Classification } & Linear classification & breast cancer tumor & Housing transaction \\
\cline { 2 - 4 } & SVM & Handwritten numeric & HD Index fluctuation \\
\cline { 2 - 5 } & Naive Bayes & News Category & Human motion state \\
\cline { 2 - 5 } & KNN & Irises & Human motion state \\
\cline { 2 - 5 } & Decision tree & The Titanic ship wreck & Human motion state \\
\hline \multirow{2}{*}{ Regression } & Logistic、Bayesian & Boston house price & \\
\hline Clustering & K-means、DBSCAN & Handwritten numeric & Consumption level \\
\hline Dimension-Reduction & PCA、NMF & Handwritten numeric & Irises、 Olivetti Face \\
\hline Neural Network & BP、MLP & MNIST & DBRHD \\
\hline
\end{tabular}

\subsection{Taking the competition as the starting point, focusing on the teaching methods reform}

Data mining courses take the student employment and current market needs into account, as well as the practical characterized of the course itself. Therefore, in the teaching process, teachers should pay more attention to combining theory with practice,and pay attention to cultivating students' ability to solve practical problems. By organizing students to participate in related competitions, teachers determine the research objectives of each research group, at the same time require mutual exchange and study. In addition to imparting basic theoretical knowledge in classroom teaching, teachers should combine research tasks with competition examples as an entry point to analyze data mining in internet log analysis, e-mail analysis, internet advertisement mining, e-commerce, mobile internet, Meteorology and other major applications in the field of practical application and success stories. In this way, not only the course itself will be away from the boring theory, but also increase students' perceptual knowledge of data mining and stimulate students in learning.

At the beginning of the course, students will be organized to participate in the competition topic 
which they are interested in. During the course teaching, teachers can combine the above competition topics and select relevant cases to add case teaching modules. The project leader will organize the guiding team includes experienced teachers to enter each competition group to carry out specific technical guidance respectively and urge the project to be implemented.

\subsection{Combining the competition activities to improve the curriculum evaluation system}

since data mining course is a practical course, the corresponding assessment method should be different from other professional courses and pay more attention to the performance of students in the learning process and ability to enhance. Part of the theoretical knowledge of the assessment mainly based on the way the test paper assessment, focused on the basic concepts of data mining, mining process and master the mastery of the algorithm.

For practical skills assessment, in addition to reflecting the students grasp of the basic theory, more importantly, to reflecting the students ability to solve practical problems. Assessments are based on competition participation and awards, and as a major part of the total score.

\section{Conclusion}

Blended learning combines the advantages of traditional classroom teaching with SPOC, and realizes the teaching concept of "taking students as the theme and teachers as the leading". This paper introduces competition-driven into blended learning and builds a knowledge system of data mining courses based on competition-driven .

Focusing on the teaching methods reform that combines theory and practice,so that competitions can be a useful supplement to daily teaching.Combined with competition activities to improve curriculum assessment system.After practice,preliminary verified its feasibility and effects.

\section{Acknowledgements}

This work is supported by the research project on the reform of degree and postgraduate education in Education Department of Jiangxi Province ( JX YJG-2015 -012 ). Nanchang University Teaching Reform Proje (NCUJGLX-17-57).

\section{References}

[1]Puplampu, Anna B,Blended learning for Project Management,ARCOM 2008, p943-952, 2008

[2]Y.Harrison Hao,Learning from Practice: Improving Blended Learning Strategies in a College Curriculum, ISET 2015, p 68-71, 2016

[3]Buzadjija, Nevzudin,An approach in studying the efficiency of blended learning system,23rd DAAAM v1, p 233-236, 2012 